\title{
Degradation processes in encapsulated ZnS:Cu powder electroluminescent phosphors
}

\author{
K.O. Popovych \\ Uzhgorod National University, 46, Pidhirna str., 88000 Uzhgorod, Ukraine \\ E-mail: atr@mail.uzhgorod.ua
}

\begin{abstract}
In this paper we present experimental results of the studying degradation processes in electroluminescent panels, prepared from encapsulated $\mathrm{ZnS}$ :Cu powder phosphors and theoretical simulation of energy parameters for the phosphor. Energy band diagrams $\mathrm{ZnS}, \mathrm{Cu}_{2} \mathrm{~S}, \mathrm{ZnS}-\mathrm{Cu}_{2-\mathrm{x}} \mathrm{S}$ heterojunction and $\mathrm{Cu}-\mathrm{ZnS}$ metal-semiconductor junction have been constructed and cohesive energies for $\mathrm{Zn}-\mathrm{S}$, Cu-S, Zn-O, Cu-O and $\mathrm{Zn}-\mathrm{Cu}$ bonds have been calculated by the method based on a linear combination of atomic orbitals and pseudo-potential. Time dependences of brightness have been found to adequately fit a two-component exponential dependence. The first part of the exponential curve has been attributed to the diffusion processes taking place in $\mathrm{Cu}_{2-\mathrm{x}} \mathrm{S}$, and the second one to the diffusion of $\mathrm{Cu}$ in $\mathrm{ZnS}$ matrix.
\end{abstract}

Keywords: electroluminescence, ZnS:Cu powder phosphor, degradation, heterostructure, electronic structure, cohesive energy.

Manuscript received 03.12.07; accepted for publication 19.12.07; published online 20.02.08.

\section{Introduction}

The main problem arising in application of electroluminescent (EL) panels prepared from $\mathrm{ZnS}: \mathrm{Cu}$ powder phosphors is loss in the emission brightness. The respective degradation mechanism in luminescent $\mathrm{ZnS}$ phosphors has been the focus of attention for a long time and it is still not clearly understood [1-6]. Different mechanisms of electroluminescence depending on the energy level structure and local field strength, e.g., injection and excitation mechanisms are assumed and confirmed by the experimental studies in ZnS phosphors [7]. The process of brightness decay is thought to be partially related to the structural relaxation at $\mathrm{ZnS}$ $\mathrm{Cu}_{2-\mathrm{x}} \mathrm{S}$ and/or $\mathrm{Cu}-\mathrm{ZnS}$ interfaces promoting copper diffusion, especially in the presence of sulphur vacancies [6].

The purpose of this work is to determine general relationships for time changes in brightness during operation of EL panels prepared from encapsulated ZnS: $\mathrm{Cu}$ powder phosphors, and to gain an understanding of the degradation mechanism. For the latter, we have performed additional theoretical calculations of the energy band diagram for $\mathrm{ZnS}-\mathrm{Cu}_{2-\mathrm{x}} \mathrm{S}$ heterostructure, $\mathrm{Cu}-\mathrm{ZnS}$ metal-semiconductor junction, and also cohesive energy for $\mathrm{Zn}-\mathrm{S}$ and $\mathrm{Cu}-\mathrm{S}$ bonds.

\section{Experimental and computational details}

Degradation processes were investigated on EL panels prepared from $\mathrm{ZnS}$ : $\mathrm{Cu}$ powder of the following trade marks: ANE, Durel, GG and GGL provided by different manufacturers.

The brightness changes of EL panels have been studied during continuous operation at $400 \mathrm{~Hz}$ frequency with voltage of $115 \mathrm{~V}$ in the time range from 0 to 2000 hours at intervals of 0.5 hour by using the tailor-made device [8].

Theoretical calculation of the energy band diagram for $\mathrm{ZnS}-\mathrm{Cu}_{2-\mathrm{x}} \mathrm{S}$ heterojunction has been performed by the method based on the linear combination of atomic orbitals and pseudo potential [9] with the atomic terms calculated within Hartree-Fock approximation. Details of the computation procedure can be found in our previous paper where we have presented results of calculations of the energy band diagram and gap states for $\mathrm{ZnS}$ : $\mathrm{Cu}, \mathrm{Cl}$ [10]. Energy band diagrams for heterostructures and metalsemiconductor junctions have been computed following the procedure given in Ref. [11].

Cohesive energy was determined as:

$$
E_{\mathrm{coh}}=\left(2-\alpha_{c}^{2}\right) \sqrt{V_{2}^{2}+V_{3}^{2}}+\frac{9}{8} \frac{\alpha_{c}^{4}\left(V_{1+}^{2}+V_{1-}^{2}\right)}{\sqrt{V_{2}^{2}+V_{3}^{2}}}-E_{\mathrm{pro}} \text {, }
$$




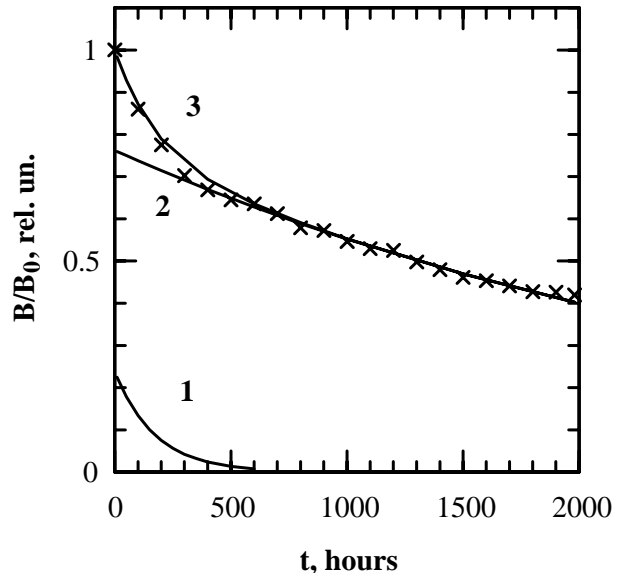

Fig. 1. Time changes in brightness for electroluminescent panel in continuous operation $(400 \mathrm{~Hz}, 115 \mathrm{~V}$ ) (crosses). Theoretical curves 1, 2 and 3 are the first second, and the sum of 1 and 2 terms in Eq. (2), respectively.

with the promotion energy $E_{\mathrm{pro}}=\left(\varepsilon_{\mathrm{p}+}-\varepsilon_{\mathrm{p}-}\right) / 2+V_{1+}+V_{1-}$; $\alpha_{c}$ - covalency; $V_{1}, V_{2}$ and $V_{3}$ - matrix elements characterizing the metallic energy, covalent energy, and polar energy [9].

\section{Results}

Fig. 1 shows relative changes in brightness $\left(B / B_{0}\right)$ with time $(t)$ for one of the EL panel types (GG43 pigment). Our graphic analysis of relaxation curves has shown that they can be approximately described by an empiric formula containing at least two components

$B / B_{0}=\alpha \exp \left(-t / \tau_{1}\right)+\beta \exp \left(-t / \tau_{2}\right)$,

with $\alpha$ and $\beta$ - numerical coefficients $(\alpha+\beta=1)$, $\tau_{1}$ and $\tau_{2}-$ relaxation times. These parameters for different types of EL panels are given in Table 1 along with $\tau_{0.5}$ time interval of the decrease by half of the initial brightness $\left(B_{0}\right)$ for EL panel.

Fig. 2 shows the formation of the energy band from the atomic terms $\mathrm{Zn} 4 p, \mathrm{Zn} 4 s, \mathrm{~S} 3 p$ for $\mathrm{ZnS}$ (a) and S $3 s$ $\left(\mathrm{Cu} s, \mathrm{~S} \mathrm{p}\right.$ ) for $\mathrm{Cu}_{2} \mathrm{~S}$ (b). Experimental data for the photoemission threshold and optical band gap (in electron-volts) are given in parentheses for comparison.

The results of energy band diagram calculations for $\mathrm{ZnS}$ and $\mathrm{Cu}_{2} \mathrm{~S}$ compounds enabled construction of the energy band diagrams for $\mathrm{ZnS}-\mathrm{Cu}_{2} \mathrm{~S}$ heterostructure and $\mathrm{Cu}-\mathrm{ZnS}$ metal-semiconductor junction shown in Figures 3a and b, respectively.

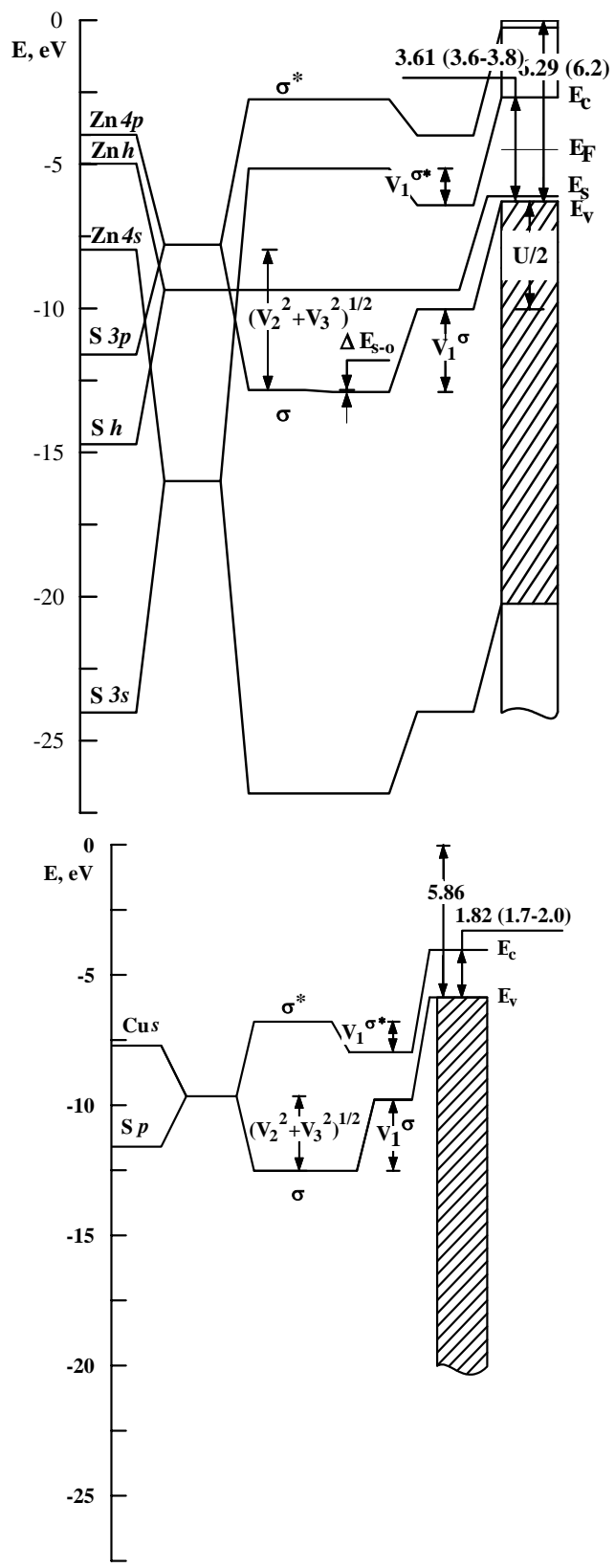

Fig. 2. Formation of the of energy band from the atomic terms for $\mathrm{ZnS}$ (a) and $\mathrm{Cu}_{2} \mathrm{~S}$ (b): $\mathrm{Zn} 4 p, \mathrm{Zn} 4 s, \mathrm{~S} 3 p$ and $\mathrm{S} 3 s$ (Cu s, $S p$ ), - atomic terms; bonding $\sigma$ and antibonding $\sigma^{*}$ states; spin-orbital splitting $\Delta E_{s-o}$; the metallicity energy over bonding $\mathrm{V}_{1}{ }^{\sigma}$ and antibonding $\mathrm{V}_{1}{ }^{\sigma^{*}}$ states; intra-atomic Coulomb repulsion $\mathrm{U} / 2$. Calculated and experimental (given in parentheses) data for the photoemission threshold and optical band gap are given in electron-volts.

Table 1. Parameters of electroluminescent panels (CM - capsule material, $d_{1}$ - phosphor thickness, $d_{2}-$ thickness of dielectric, $C_{0}-$ initial capacity, $B_{0}-$ initial brightness) and relaxation parameters according to Eq. (2).

\begin{tabular}{|c|c|c|c|c|c|c|c|c|c|c|}
\hline \multirow{2}{*}{ Pigment } & \multicolumn{4}{|c|}{ Parameters of EL panels } & \multicolumn{5}{c|}{ Relaxation parameters } \\
\cline { 2 - 12 } & $\mathrm{CM}$ & $d_{1}(\mu \mathrm{m})$ & $d_{2}(\mu \mathrm{m})$ & $C_{0}(\mathrm{nf})$ & $B_{0}\left(\mathrm{Cd} / \mathrm{m}^{2}\right)$ & $\alpha$ & $\beta$ & $\tau_{1}$ (hours) & $\tau_{2}$ (hours) & $\tau_{0.5}$ (hours) \\
\hline GG43 & $\mathrm{Al}_{2} \mathrm{O}_{3}$ & 44 & 20 & 4.27 & 129 & 0.238 & 0.762 & 174 & 3100 & 1300 \\
\hline $\mathrm{GGL} 43$ & $\mathrm{Al}_{2} \mathrm{O}_{3}$ & 36 & 19 & 4.13 & 82 & 0.133 & 0.867 & 87 & 4100 & 2300 \\
\hline Durel & $(\mathrm{Ti}-\mathrm{Si}) \mathrm{O}_{2}$ & 45 & 20 & 4.20 & 105 & 0.262 & 0.738 & 145 & 3100 & 1200 \\
\hline $\mathrm{ANE}$ & $\mathrm{AlN}$ & 33 & 22 & 4.31 & 79 & 0.191 & 0.809 & 217 & 3100 & 1500 \\
\hline
\end{tabular}

(C) 2007, V. Lashkaryov Institute of Semiconductor Physics, National Academy of Sciences of Ukraine 

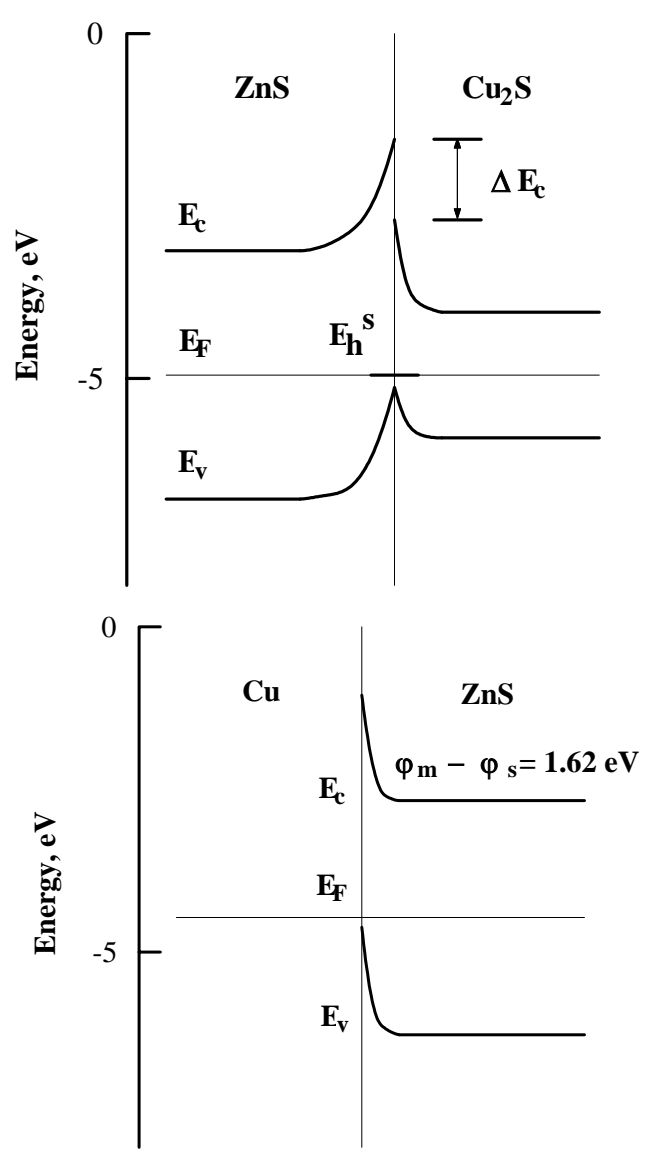

Fig. 3. Energy band diagrams for $\mathrm{ZnS}-\mathrm{Cu}_{2} \mathrm{~S}$ heterostructure (a) and $\mathrm{Cu}-\mathrm{ZnS}$ metal-semiconductor junction (b).

The results of calculation of the cohesive energy are listed in the Table 2, where summarized are the interatomic distance $(d)$, promotion energy $\left(E_{\text {pro }}\right)$, covalency $\left(\alpha_{c}\right)$, level splitting energy $\left(\left(V_{2}^{2}+V_{3}^{2}\right)^{1 / 2}\right)$, components of cohesive energy and its value for most probable compounds and bondings in the phosphors under investigation. For the Zn-S bond cohesive energy has been found to be $1.14 \mathrm{eV}$, while the energy of the cohesive bond $\mathrm{Cu}-\mathrm{S}$ was about $0.77 \mathrm{eV}$. Therefore, the first part of the relaxation curve (Eq. (2)) is attributed to the diffusion processes taking place in $\mathrm{Cu}_{2-\mathrm{x}} \mathrm{S}$, when the second one could be attributed to the diffusion of $\mathrm{Cu}$ in ZnS matrix.

\section{Discussion}

Let us discuss the problem of brightness degradation under the assumption that in $\mathrm{ZnS}$ : $\mathrm{Cu}$ crystals there are linear dislocations arising at the boundary between crystallites with the hexagonal and cubic structures where $\mathrm{Cu}_{2-\mathrm{x}} \mathrm{S}$ inclusions can be found.

It is known that there is an elastic stress field around dislocations in crystal interacting with stress fields arising around impurity atoms [2]. The energy of this interaction is determined by the following expression:
Table 2. Interatomic distance $(d)$, promotion energy $\left(E_{\text {pro }}\right)$, covalency $\left(\alpha_{c}\right)$, level splitting energy $\left(\left(V_{2}^{2}+V_{3}^{2}\right)^{1 / 2}\right)$, components of cohesive energy and its value $\left(E_{\text {coh }}\right)$.

\begin{tabular}{|c|c|c|c|c|c|}
\hline \multirow{2}{*}{ Parameters } & \multicolumn{5}{|c|}{ Compound } \\
\cline { 2 - 6 } & $\mathrm{ZnS}$ & $\mathrm{Cu}_{2} \mathrm{~S}$ & $\mathrm{ZnO}$ & $\mathrm{CuO}$ & $\mathrm{ZnCu}$ \\
\hline$d, \mathrm{~nm}$ & 0.235 & 0.240 & 0.198 & 0.201 & 0.266 \\
\hline$E_{\mathrm{pro}}, \mathrm{eV}$ & 7.91 & 8.05 & 11.70 & 11.84 & 2.13 \\
\hline$\alpha_{\mathrm{c}}$ & 0.654 & 0.610 & 0.588 & 0.557 & 0.992 \\
\hline$\left(V_{2}^{2}+V_{3}^{2}\right)^{1 / 2}, \mathrm{eV}$ & 5.04 & 5.23 & 7.91 & 8.10 & 2.59 \\
\hline $\begin{array}{c}\left(2-\alpha_{\mathrm{c}}^{2}\right)\left(V_{2}^{2}+V_{3}^{2}\right)^{1 / 2}, \\
\mathrm{eV}\end{array}$ & 7.92 & 8.51 & 13.09 & 13.69 & 2.63 \\
\hline $\begin{array}{c}{ }_{9}^{4}{ }_{\mathrm{c}}\left(V_{1+}^{2}+V_{1-}^{2}\right) / \\
2\left(V_{2}^{2}+V_{3}{ }^{2}\right), \mathrm{eV}\end{array}$ & 0.43 & 0.31 & 0.33 & 0.26 & 0.68 \\
\hline$E_{\mathrm{coh}}, \mathrm{eV}$ & 1.14 & 0.77 & 1.72 & 2.11 & 1.19 \\
\hline
\end{tabular}

$E=-\frac{4}{3} \frac{G \varepsilon R^{3}(1+\gamma) b}{1-\gamma} \frac{\sin \vartheta}{r}$,

with $G$ - shear modulus, $R(1+\varepsilon)$ - impurity atom radius, $R$ - average radius of solvent atoms, $b$ - Burgers vector, $\gamma$ - Poisson's ratio, $r$ - distance between a dislocation and impurity, $\theta$ - polar angle between the direction of sliding and radius-vector. Since the size of the $\mathrm{Cu}$ impurity atom is smaller than that for $\mathrm{Zn}$ atom $(\varepsilon<0)$, the bonding energy is positive, and these atoms are attracted into the contraction region in the elastic stress field of an edge dislocation. Therefore, in our case we should account both for diffusion flow of $\mathrm{Cu}$ atoms towards the dislocation as binding boundary and drift flow in the elastic stress field with the same direction as the diffusion one.

Allowing for diffusion and drift flows, we derive the differential equation describing the impurity concentration $(N)$ changes in the volume of semiconductor when impurity is condensated on dislocations as:

$$
\frac{1}{D} \frac{\partial N}{\partial t}=\frac{\partial^{2} N(r, t)}{\partial t^{2}}+\left(\frac{1}{r^{2}}+\frac{1}{r}\right) \frac{\partial N(r, t)}{\partial r}-\frac{L}{r^{3}}(N(r, t)),
$$

with $D$ - diffusion coefficient and $L=E r / k T$. The first term of this equation describes the diffusion flow, the other two describe the drift one.

An approximate solution of the Eq. (4) with long times $(t \rightarrow \infty)$ and allowance for the probability of $\mathrm{Cu}$ impurity atom extraction from dislocation and their turning back into the semiconductor can be described by the expression [12]

$$
N_{t}=N_{0}\left[e^{-\alpha t}-\left(1-e^{-\alpha t}\right) e^{-E / k T}\right]
$$

where $\alpha=2 \pi N_{D} D, N_{D}$ is the dislocation density, $N_{0}$ and $N_{t}$ are impurity concentrations in semiconductor, initial and in $t$ moment, respectively.

The given relationship adequately describes the observed experimental time and temperature 
dependences for brightness degradation of EL panels (Fig. 1). In terms of this model, at the initial stage of degradation when $\mathrm{Cu}$ atoms are settled at dislocations the binding energy between a $\mathrm{Cu}$ atom and dislocation is high $[\exp (-E / \mathrm{k} T)<<1]$ and concentration decrease is described only by the first term of Eq. (5). Then, as $\mathrm{Cu}$ atoms are precipitated farther and farther from the dislocation centre ( $r$ increases) the value of $E$ decreases and the degradation rate goes down. This results in at least two exponential parts in dependences of brightness on the operation time (Fig. 1). To obtain more precise interpretation of the experimental result, it is necessary to take into consideration the changes in concentration of the emitting centres at the vacancy associations, some complexes, etc.

\section{Conclusions}

Degradation processes in electroluminescent panels prepared from encapsulated $\mathrm{ZnS}$ : $\mathrm{Cu}$ powder phosphors in continuous operation $(400 \mathrm{~Hz}, 115 \mathrm{~V})$ in the time range from 0 to 2000 hours have been studied. It has been found that operation time dependences of brightness adequately fit a two-component exponential dependence. Calculated energy band diagrams and cohesive energy allowed inference that the first part of the relaxation curve may be attributed to the diffusion processes taking place in $\mathrm{Cu}_{2-\mathrm{x}} \mathrm{S}$, and the second one to the diffusion of $\mathrm{Cu}$ inside the $\mathrm{ZnS}$ matrix.

\section{References}

1. S. Roberts, Aging characteristics for electroluminescent phosphors // J. Appl. Phys. (Suppl.) 28, p. 262-265 (1957).

2. N.N. Grigoriev and Yu.A. Kulyunin, Some results of the studies of phosphor damage process during electroluminescence // Optika $i$ spektroskopiya 10(6), p. 780-786 (1961) (in Russian).

3. N.P. Soshchin and I.N. Oplov, Electrochemical nature of aging of electroluminescent phosphor / in:
Electroluminescence of Solids // Proc. III Electroluminescence Meeting (Tartu; July 1969), p. 279283. Naukova Dumka, Kiev (1971) (in Russian).

4. V.V. Pasynkov, J.A. Saveljev and N.N. Semenov. On the problem of formation and aging of d.c. electroluminescent components based on $\mathrm{ZnS}(\mathrm{Cu}$, $\mathrm{M}, \mathrm{Cl}$ ) sublimatphosphor / in: Electroluminescence of Solids // Proc. III Electroluminescence Meeting (Tartu; July 1969), p. 242-246. Naukova Dumka, Kiev, 1971 (in Russian).

5. J.W. Mayo, P. Hutchinson, J.L. Hinsley, P.W. Alexander and M. Davis, An Interactive 2000Character DCEL Display System // SID Int. Symp. Digest 1986, Paper 17.4, p. 313-315 (1986).

6. N.E. Brese, C.L. Rohrer and G.S. Rohrer, Brightness degradation in electroluminescent $\mathrm{ZnS}: \mathrm{Cu} / /$ Solid State Ionics 123, p. 19-24 (1999).

7. W.W. Piper and E.E. Williams, The mechanism of electroluminescence of zinc sulfide // Br. J. Appl. Phys. (Suppl.) 6, S39-S44 (1955).

8. K. Popovych, Yu. Nakonechny, I. Rubish, V. Gerasimov and G. Leising, The study of the lifetime of ZnS-based luminescent films by using the devices of series LMS // Semiconductor Physics, Quantum Electronics \& Optoelectronics 6(4), p. 520-523 (2003).

9. W.A. Harrison, Elementary Electronic Structure. World Scientific Publishing Co., New Jersey, London, Singapore, et al., 2004.

10. N.D. Savchenko, T.N. Shchurova, K.O. Popovych, I.D. Rubish and G. Leising, Simulation of the electronic states in the band gap for $\mathrm{ZnS}: \mathrm{Cu}, \mathrm{Cl}$ crystallophosphors // Semiconductor Physics, Quantum Electronics \& Optoelectronics 7(2), p. 133-137 (2004).

11. A.D. Milns and D.L. Feucht, Heterojunctions and Metal-Semiconductor Junctions. Academic Press, New-York and London, 1972.

12. A.H. Cottrell and B.A. Bilby, Dislocation theory of yielding and strain ageing of iron // Proc. Phys. Soc. A 62(1), p. 49-62 (1949). 